\title{
$S_{S}$ Sustalinable Chemistry\& Engineering

\section{Lignin-to-Liquid-Solvolysis (LtL) of Organosolv Extracted Lignin}

\author{
Camilla Løhre, ${ }^{*} \dagger \odot$ Gro-Anita Aakre Laugerud, ${ }^{\dagger}$ Wouter J. J. Huijgen, ${ }^{\ddagger}$ and Tanja Barth ${ }^{\dagger}$ \\ ${ }^{\dagger}$ Department of Chemistry, University of Bergen, Allégt. 41, 5007 Bergen, Norway \\ ${ }^{*}$ Biomass \& Energy Efficiency, Energy Research Centre of The Netherlands (ECN), Westerduinweg 3, 1755 LE, Petten, The \\ Netherlands
}

\section{Supporting Information}

ABSTRACT: Utilization of lignocellulosic biomass as a future energy source is a research field of widespread growth. The lignin fraction has potential as a renewable resource to provide building blocks for the chemical industry and is the most prominent source of bio-based aromatics. Lignin, combined with formic acid and water under high temperature and pressure, is converted to a bio-oil rich in alkylated phenols and aliphatic hydrocarbons in a unique conversion process termed the LtL-process (lignin-to-liquid). In this work, this conversion technique has shown to be applicable to a variety of lignins,
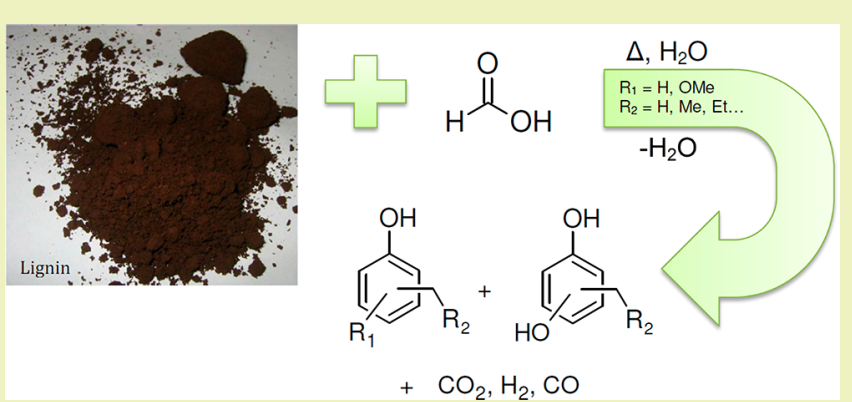
with organosolv extracted lignin as the main focus because of its high purity. The organosolv lignins appeared to be well suited for LtL-conversion generating higher yields of bio-oil than a lignin-rich residue from enzymatic hydrolysis. ${ }^{31} \mathrm{P}$ NMR and GC-MS showed that the $\mathrm{O} / \mathrm{C}$ ratios of the bio-oils decreases with increasing reaction temperature during LtL-solvolysis because of a decrease in methoxylated phenols and an increase in phenols with no methoxy substituent. This was verified by partial least-squares (PLS) regression analysis and elemental analysis of the feedstocks and resulting bio-oils, from which an effective hydrodeoxygenation during LtL-conversion was evident too.

KEYWORDS: Lignin, Organosolv, Thermochemical conversion, Hydrodeoxygenation, Lignin-to-liquid, Phenols

\section{INTRODUCTION-PURPOSE OF THE WORK}

The interest in using lignocellulosic biomass (LCBM) as a future renewable feedstock is rapidly expanding. Sustainable and feasible utilization of LCBM aims to take advantage of all its constituents and building blocks. In this endeavor, the concept of a "biorefinery" has been developed, and it involves processes and technologies used for converting the biomass to a variety of fuels and value-added chemicals. ${ }^{1}$ For complete utilization of the feedstock, pretreatment or fractionation is needed to separate and access the major biomass constituents, that is, the carbohydrates comprising cellulose and hemicellulose, and the aromatic lignin polymer. Ongoing research efforts address a variety of methods, such as acid/enzymatic hydrolysis, alkaline degradation, steam explosion, and organosolv. ${ }^{2}$ The properties and quality of the fractions are a function of the method used in the fractionation, and thus, the choice of method could influence the results of further conversion steps.

Organosolv fractionation is a pretreatment process, which uses an organic solvent or mixture of organic solvents with water to remove lignin, most often as a preprocessing step before enzymatic hydrolysis of the cellulose fraction. ${ }^{3}$ Numerous publications regarding organosolv fractionation have been reported in the literature during previous years, documenting the high purity of both the cellulose and lignin fractions obtained. Many publications primarily focus on utilization of the cellulose fraction after organosolv fractionation and optimization of reaction conditions with regard to the cellulose quality. ${ }^{4-8}$ However, the lignin fraction, which is one of the three major constituents of LCBM, ${ }^{1}$ can also be transformed into value-added chemicals if due regard is given to its complex and valuable structure. Lignin is a cross-linked amorphous copolymer synthesized from random polymerization of the three primary phenylpropane monomers; paracoumaryl alcohol (H-lignin), coniferyl alcohol (G-lignin), and sinapyl alcohol (S-lignin). The monomers are bonded through different $\mathrm{C}-\mathrm{O}-\mathrm{C}$ and $\mathrm{C}-\mathrm{C}$ interunit linkages, and the lignin concentration within LCBM varies from species to species. ${ }^{9}$ Lignin is the most important source of bio-based aromatics and can, subsequently, act as a provider of aromatic products, such as vanillin, adhesives, phenols, and other fine chemicals in addition to aromatic motor fuel components. ${ }^{10-14}$

Various methods have been, and are being, tested to develop high-yield processes for utilization of lignin. ${ }^{15-18}$ One such process was reported by Kleinert and Barth in 2008, and comprises thermochemical conversion (hydrodeoxygenation) of lignin in a solvent with an in situ hydrogen donor, ${ }^{10,19}$ which in this case is formic acid (FA). This approach is denoted the LtL (lignin-to-liquid) process and aims to produce a bio-oil containing a mixture of monomeric alkylated phenols and aliphatic hydrocarbons. A number of papers on this approach

Received: September 1, 2017

Revised: December 14, 2017

Published: January 8, 2018 
Table 1. Feedstock Characteristics ${ }^{a}$

\begin{tabular}{|c|c|c|c|c|c|}
\hline \multirow{2}{*}{$\begin{array}{l}\text { Feed- } \\
\text { stock }\end{array}$} & \multirow{2}{*}{ Characteristics } & \multicolumn{2}{|c|}{ Ratio } & \multirow{2}{*}{$\begin{array}{c}\text { Lignin } \\
\text { Content } \\
(\%)\end{array}$} & \multirow{2}{*}{$\begin{array}{c}\text { Ash } \\
\text { Content* } \\
(\%)\end{array}$} \\
\hline & & $\mathbf{H} / \mathbf{C}$ & $\mathrm{O} / \mathrm{C}$ & & \\
\hline EEH & $\begin{array}{l}\text { Eucalyptus - } \\
\text { Origin: Thailand, produced at Biorefinery Demo Plant } \\
\text { (BDP) in Örnsköldsvik, Sweden } \\
\text { Lignin rich residue resulting from mild acid pretreatment } \\
\text { followed by Enzymatic Hydrolysis }\end{array}$ & 1.53 & 0.74 & $\sim 50 * *$ & $\sim 4$ \\
\hline EEHO & $\begin{array}{l}\text { Eucalyptus - } \\
\text { Origin: Thailand, produced at University of Bergen (UoB), } \\
\text { Norway } \\
\text { Lignin rich residue after Enzymatic Hydrolysis processed } \\
\text { with Organosolv conditions: } \\
178^{\circ} \mathrm{C} \text {, EtOH- } \mathrm{H}_{2} \mathrm{O} 63 \% \mathrm{w} / \mathrm{w} \text {, without acid, } 3 \text { h } 20 \mathrm{~min} \text { [25] }\end{array}$ & 1.12 & 0.34 & ND & $<0.6$ \\
\hline BO & $\begin{array}{l}\text { Birch - } \\
\text { Origin: Finland, produced at Energy research Centre of the } \\
\text { Netherlands (ECN), The Netherlands } \\
\text { Organosolv conditions: } \\
200^{\circ} \mathrm{C} \text {, EtOH- } \mathrm{H}_{2} \mathrm{O} 50 \% \mathrm{w} / \mathrm{w}, 5 \mathrm{mM} \mathrm{H}_{2} \mathrm{SO}_{4}, 30 \mathrm{~min} \\
\text { carbohydrates }<<1 \% \mathrm{w} / \mathrm{w}\end{array}$ & 1.16 & 0.32 & $96.4 * * *$ & $<0.9$ \\
\hline WSO & $\begin{array}{l}\text { Wheat Straw - } \\
\text { Origin: Champagne-Ardennes region, France, produced at } \\
\text { Energy research Centre of the Netherlands (ECN), The } \\
\text { Netherlands } \\
\text { Organosolv conditions: } \\
210^{\circ} \mathrm{C} \text {, EtOH- } \mathrm{H}_{2} \mathrm{O} 50 \% \mathrm{w} / \mathrm{w} \text {, without acid, } 90 \mathrm{~min} \\
\text { carbohydrates }<<1 \% \mathrm{w} / \mathrm{w}\end{array}$ & 1.14 & 0.27 & $>95 * * *$ & $<0.9$ \\
\hline
\end{tabular}

$a_{*}$ Ash content was measured by combustion at $575^{\circ} \mathrm{C}$ according to protocol NREL/TP-510-42622. ${ }^{26} * *$ Estimated from elemental composition. ***Sum of AIL (acid insoluble) and ASL (acid soluble) lignin was determined using analytical procedures described in Wildschut et al. (2013). ${ }^{7}$

have been published addressing subjects, such as reaction mechanisms, ${ }^{20}$ kinetic modeling ${ }^{21}$ and the use of catalyst to increase energy efficiency. ${ }^{22,23}$ Formic acid can also be used in organosolv fractionation, ${ }^{24}$ which suggests the potential for a future combined process.

The primary aim of the work presented here is to evaluate the impact of LCBM pretreatment via organosolv lignin separation on yield and composition of phenolic bio-oils from subsequent thermochemical conversion. The main research question is whether lignin from organosolv pretreatment is suitable for the lignin-to-liquid-technique (LtL). Lignins from three hardwood materials and wheat straw are screened and the bio-oils are produced in a water/FA-based LtL-solvent system. The oil yields are quantified, and the molecular composition is investigated using GC-MS. In addition, ${ }^{31} \mathrm{P} \mathrm{NMR}$ is used to analyze the type of hydroxyl $(-\mathrm{OH})$ groups present in the oils, and the results are compared to semiquantitative GC-MS results to evaluate the distribution of phenolic monomers present in the bio-oils according to experimental conditions. Oxygen content and corresponding degree of deoxygenation as a result of the LtL-solvolysis are investigated by elemental analysis.

\section{EXPERIMENTAL SECTION}

Feedstock Characterization. The feedstock used in this work is given in Table 1.

Feedstock EEH is a lignin -rich residue resulting from mild acid pretreatment followed by enzymatic hydrolysis of eucalyptus produced at SEKAB in Sweden. EEHO is EEH-treated under organosolv extraction conditions to purify and isolate the lignin fraction of the feedstock. BO and WSO are lignin from birch and wheat straw, respectively, isolated using organosolv extraction. BO and WSO were kindly supplied by the Energy Research Centre of The Netherlands (ECN), prepared as described in Wildschut et al. (2013) using a $20 \mathrm{~L}$ batch autoclave reactor. ${ }^{7}$

Reagents and solvents were purchased from Sigma-Aldrich and used without further purification $(\geq 98 \%)$. Ethanol, absolute prima, was purchased from Kemetyl Norway AS.

Organosolv Extraction of EEH. Eucalyptus residue from enzymatic hydrolysis was treated with a 63 wt \% mixture of ethanol in distilled water, at a solvent-feedstock ratio of $20: 1 \mathrm{~mL} / \mathrm{g}(\mathrm{dw})$, in a $250 \mathrm{~mL}$ high pressure reactor from the 1834-series equipped with a pressure gauge. $^{27}$ The high solvent to feedstock ratio was selected since the feedstock is a lignin-rich residue and not wood chips, pellets, or similar. The reactor was placed in a 4923EE heating mantle controlled by a $4842 \mathrm{EW}$ temperature controller. All items were purchased from Parr instruments. After processing at $178{ }^{\circ} \mathrm{C}$ for $3 \mathrm{~h}$ and $20 \mathrm{~min}^{25}$ the reactor was taken out of the heating mantle and cooled to ambient temperature. Nondissolved fibers were filtered off before the solvent was removed from the organosolv liquor at $40{ }^{\circ} \mathrm{C}$ using a rotary evaporator. A reddish-brown solid residue was left after solvent evaporation and was dried at ambient temperature for 4 days before LtL-solvolysis.

Generation of feedstock EEHO by organosolv extraction of EEH resulted in an average yield of $20 \%$ precipitated material (lignin) based on initial EEH mass input. The low yield may be due to the preprocessing, in particular lignin condensation during mild acid pretreatment, or due to suboptimal organosolv treatment conditions. 
Experimental Design. An experimental design was set up to explore the effect of selected experimental factors on the amount and composition of the products from LtL-solvolysis. Experimental variables were (1) loading of hydrogen donor (mL FA) and (2) reaction temperature $\left({ }^{\circ} \mathrm{C}\right)$. A high and low value for the variables was selected for use in the design, together with intermediate points. Reaction duration, lignin loading, and loading of distilled water were kept constant, and parameters were selected based on previously published work. $^{28-31}$ Table 2 gives an overview of the experimental

Table 2. Experimental Design Setup for Six Experiments with Low $(-)$, Intermediate (0), and High $(+)$ Levels for the Variables V1 (FA Loading, $\mathrm{mL}$ ) and V2 (Reaction Temperature, ${ }^{\circ} \mathrm{C}$ )

$\begin{array}{ccccccc}\text { experiment } & -- & +- & 00 \mathrm{I} & 00 \mathrm{II} & -+ & ++ \\ \text { V1 } & - & + & 0 & 0 & - & + \\ \text { V2 } & - & - & 0 & 0 & + & +\end{array}$

design. The design was repeated for all four feedstocks giving a total set of $24 \mathrm{LtL}$-experiments. Experimental details: V1 $(-)=0.50 \mathrm{~mL}, \mathrm{~V} 1$ $(0)=0.75 \mathrm{~mL}, \mathrm{~V} 1(+)=1.00 \mathrm{~mL}, \mathrm{~V} 2(-)=320^{\circ} \mathrm{C}, \mathrm{V} 2(0)=340^{\circ} \mathrm{C}$, and V2 $(+)=360{ }^{\circ} \mathrm{C}$.

The results from the design were interpreted using principal component analysis (PCA) and Sirius 8.1 software. A biplot of a PCA reveals correlations between descriptors/loadings and their potential association with the same properties of an object. If the loadings are projected close to each other with respect to the origin they are positively correlated, and if they are projected opposite $\left(180^{\circ}\right)$ to each other with respect to the origin they are negatively correlated. Descriptors that have a strong influence on the model are projected far from the origin, and descriptors with negligible or minor influence appear close to the origin in the loading plot/biplot. ${ }^{32}$ In a partial leastsquares (PLS) regression analysis, quantitative relations can be established between blocks of variables, for example, a block of descriptor data for a series of reaction systems and a block of response data measured on these systems. ${ }^{32}$

Solvolysis System and Conditions. Feedstock and solvents were added to a $25 \mathrm{~mL}$ high pressure Parr reactor from the 4740-series without stirring and placed in a preheated Carbolite Laboratory High Temperature oven. After the completed reaction time, the reactor was taken out of the oven and cooled to ambient temperature overnight. The resulting products after solvolysis included a gas phase, a liquid phase and a small amount of solid phase. The amount of gaseous product was determined by weighting the cooled reactor before and after venting the gas. Analysis of the gas composition was not performed as part of this study, but relevant data for gas composition can be found in Bengoechea et al. (2015) showing that the main components of the gas phase are the decomposition products, $\mathrm{CO}_{2}$, $\mathrm{H}_{2}$, and $\mathrm{CO}$, of formic acid and limited amounts of light alkanes such as methane. ${ }^{22}$

The liquid product consisted of a single aqueous phase with dispersed organic particles. No analyses were performed on the aqueous product in this study except TOC analysis measuring on average $0.02 \mathrm{~g} / \mathrm{mL}$ NPOC. Dark brown, highly viscous, LtL-oil was not present as a separate phase but adsorbed on to the solid residue due to its hydrophobic character. The LtL-oil is miscible in an ethyl acetate (EtAc) and tetrahydrofuran (THF) mixture and was therefore separated from the solid phase using EtAc:THF (9:1 v/v) and filtered through $0.45 \mu \mathrm{m}$ Puradisc $25 \mathrm{~mm}$ nylon filters. The remaining aqueous phase was then extracted with EtAc:THF (9:1 v/v) three times to ensure sufficient phase separation and the organic phases were combined and dried over $\mathrm{Na}_{2} \mathrm{SO}_{4}(\mathrm{~s})$.

The solvent was removed from the LtL-oil on a rotary evaporator at a temperature of $40{ }^{\circ} \mathrm{C}$ and a pressure of 175 mbar until a stable weight for LtL-oil was achieved. This pressure is set as standard conditions for all LtL-oils to ensure reproducible workup, as previously described in published work. ${ }^{28}$
Mass Spectrometry. The LtL-oils were analyzed shortly after workup using GC-MS on an Agilent Technologies 7890A GC system coupled with an Agilent Technologies 5977A MSD. EtAc:THF (9:1 v/ v) with hexadecane $(2 \mu \mathrm{L} / \mathrm{L})$ as internal standard was used as solvent for the bio-oils and the samples were analyzed using splitless injection at $280{ }^{\circ} \mathrm{C}$ (injector temperature) on a $30 \mathrm{~m} \mathrm{HP}-5 \mathrm{~ms}$ column with 250 $\mu \mathrm{m}$ ID and thickness of $0.25 \mu \mathrm{m}$ from Agilent Technologies. A constant gas flow rate of $1 \mathrm{~mL} / \mathrm{min}$ and the following GC oven temperature program was applied as shown in Table 3.

\section{Table 3}

\begin{tabular}{|c|c|c|c|c|}
\hline $\begin{array}{l}\text { start } \\
\text { temperature }\end{array}$ & $40^{\circ} \mathrm{C}$ & $\begin{array}{l}\text { hold time } 5 \\
\text { min }\end{array}$ & & \\
\hline heating rate 1 & $6{ }^{\circ} \mathrm{C} / \mathrm{min}$ & $\begin{array}{l}\text { hold time } 0 \\
\text { min }\end{array}$ & $\begin{array}{l}\text { final } \\
\text { temperature }\end{array}$ & $280{ }^{\circ} \mathrm{C}$ \\
\hline heating rate 2 & $40^{\circ} \mathrm{C} / \mathrm{min}$ & $\begin{array}{l}\text { hold time } 5 \\
\text { min }\end{array}$ & $\begin{array}{l}\text { final } \\
\text { temperature }\end{array}$ & $300{ }^{\circ} \mathrm{C}$ \\
\hline
\end{tabular}

The GC-MS interphase valve delay was set to $4.60 \mathrm{~min}$ and the MS detector operated in positive mode with an ion-source temperature of $250{ }^{\circ} \mathrm{C}$. Compounds were detected using Enhanced MSD ChemStation software F.01.00.1903 from Agilent Technologies and identified using the NIST 2.0 library.

${ }^{31} \mathrm{P}$ NMR. The procedure for ${ }^{31} \mathrm{P}$ NMR is based on the experimental process of Jasiukaitytè et al. (2010). ${ }^{33}$

A brief summary of the procedure is as follows: $30 \mathrm{mg}$ bio-oil was dissolved in $500 \mu \mathrm{L}$ of a solution containing pyridine and deuterated chloroform $(1.6: 1 \mathrm{v} / \mathrm{v})$ and relaxation agent chromium(III)acetylacetonate $\left(\mathrm{Cr}(\mathrm{acac})_{3}\right)(5 \mathrm{mg} / \mathrm{mL})$. Cyclohexanol $(10 \mu \mathrm{L})$ was added to the sample as an internal standard.

Phosphorylation agent 2-chloro-4,4,5,5-tetramethyl-1,3,2-dioxaphospholane (TMDP; $100 \mu \mathrm{L}$ ) was then added, and the mixture was shaken vigorously and left at room temperature overnight. The prepared sample solution was transferred into a NMR tube before analysis.

The spectra were acquired using a Bruker Avance 500-instrument and processed with Bruker TopSpin 3.1. All chemical shifts reported in this paper are relative to the reaction product of water with phosphorylating reagent which was observed to give sharp signals in pyridine $/ \mathrm{CDCl}_{3}$ at $132.2 \mathrm{ppm}$. Experimental parameters for optimum resolution were adjusted on site and can be found in Table S1.

Elemental Analysis. Selected LtL-oils were analyzed by elemental analysis in CHNS mode with a VarioEL III from Elementar. The amount of oxygen was calculated by difference.

\section{RESULTS}

LtL-Solvolysis. Results from LtL-solvolysis of the feedstock presented in Table 1 are displayed in Table 4. An extended overview of input material, reaction conditions and product output can be found in Table S2.

A brief overview of yields related to reaction conditions is presented in this section and are more closely discussed in Principal Component Analysis section.

The quantitative results in Table 4 show low conversion yields of the crude EEH feedstock to bio-oil compared to the other feedstocks in this study, with oil yields ranging from 26 to $36 \mathrm{wt} \%$ relative to the input, compared to $50-73 \mathrm{wt} \%$ for the organosolv lignins. A marked increase in oil yield is observed after organosolv extraction of the eucalyptus crude, $\mathrm{EEH}$, to produce the cleaner lignin EEHO. On the average, organosolv extracted birch wood, BO, gave the highest oil yield (64 wt \% relative to lignin input) see Table 4 . Average oil yields based on feedstock are (in descending order): BO (64\%) > WSO (61\%) $>\operatorname{EEHO}(57 \%)>\mathrm{EEH}(32 \%)$. Depicted in Figure 1 are oil yields and solid yields of the 24 bio-oils comprising the sample set. Since the crude feedstock EEH is not pure due to being 
Table 4. Quantitative Results from LtL-Solvolysis ${ }^{a}$

\begin{tabular}{|c|c|c|c|c|c|c|}
\hline experiment & EEH-- & $\mathrm{EEH}+-$ & EEHOOI & EEHOOII & $\mathrm{EEH}-+$ & $\mathrm{EEH}++$ \\
\hline gas (\% of FA input) & 114.8 & 98.4 & 97.8 & 97.8 & 114.8 & 106.6 \\
\hline aqueous-phase ( $\%$ of solvent input) & 89.7 & 91.0 & 92.0 & 88.3 & 96.4 & 95.6 \\
\hline solids (\% of lignin input) & 23.7 & 18.1 & 10.1 & 15.3 & 16.1 & 11.8 \\
\hline LtL-oil yield (\% of lignin input) & 28.4 & 34.3 & 26.4 & 33.8 & 32.0 & 36.6 \\
\hline mass recovery $(\%)$ & 89.0 & 89.2 & 87.9 & 86.3 & 93.9 & 93.8 \\
\hline experiment & $\mathrm{EEHO}--$ & $\mathrm{EEHO}+-$ & EEHOOOI & EEHO00II & EEHO-+ & EEHO++ \\
\hline gas (\% of FA input) & 98.4 & 98.4 & 98.9 & 96.8 & 96.8 & 98.4 \\
\hline aqueous -phase ( $\%$ of solvent input) & 94.5 & 93.1 & 95.8 & 96.0 & 97.6 & 95.8 \\
\hline solids (\% of lignin input) & 18.4 & 16.7 & 19.8 & 17.2 & 10.3 & 8.5 \\
\hline LtL-oil yield (\% of lignin input) & 53.2 & 53.2 & 56.4 & 62.2 & 57.2 & 60.9 \\
\hline mass recovery $(\%)$ & 92.8 & 92.2 & 94.5 & 94.6 & 94.6 & 94.0 \\
\hline experiment & $\mathrm{BO}--$ & $\mathrm{BO}+-$ & BO00I & BO00II & $\mathrm{BO}-+$ & $\mathrm{BO}++$ \\
\hline gas (\% of FA input) & 98.4 & 90.2 & 87.0 & 87.9 & 98.4 & 97.6 \\
\hline aqueous -phase ( $\%$ of solvent input) & 95.1 & 95.5 & 95.4 & 94.3 & 96.0 & 99.3 \\
\hline solids (\% of lignin input) & 14.2 & 13.7 & 11.9 & 18.5 & 20.8 & 5.1 \\
\hline LtL-oil yield (\% of lignin input) & 71.8 & 72.8 & 64.9 & 56.2 & 49.9 & 68.4 \\
\hline mass recovery $(\%)$ & 94.6 & 93.6 & 92.3 & 91.4 & 93.8 & 96.7 \\
\hline experiment & WSO-- & WSO+- & WSO00I & WSO00II & WSO-+ & WSO++ \\
\hline gas (\% of FA input) & 98.4 & 97.6 & 97.8 & 97.8 & 98.4 & 98.4 \\
\hline aqueous -phase (\% of solvent input) & 94.3 & 94.0 & 97.8 & 96.9 & 91.6 & 98.6 \\
\hline solids (\% of lignin input) & 19.5 & 23.8 & 16.9 & 16.2 & 25.1 & 7.3 \\
\hline LtL-oil yield (\% of lignin input) & 61.6 & 58.2 & 61.6 & 61.9 & 54.2 & 65.8 \\
\hline mass recovery (\%) & 93.5 & 93.7 & 96.0 & 95.3 & 91.2 & 96.3 \\
\hline
\end{tabular}

${ }^{a} \mathrm{~A}$ fixed amount of $0.50 \mathrm{~g}$ of lignin and $4.0 \mathrm{~mL}$ of distilled water was added to the reactor in each experiment in addition to the varying amount of formic acid. Reaction time was kept constant at two hours.

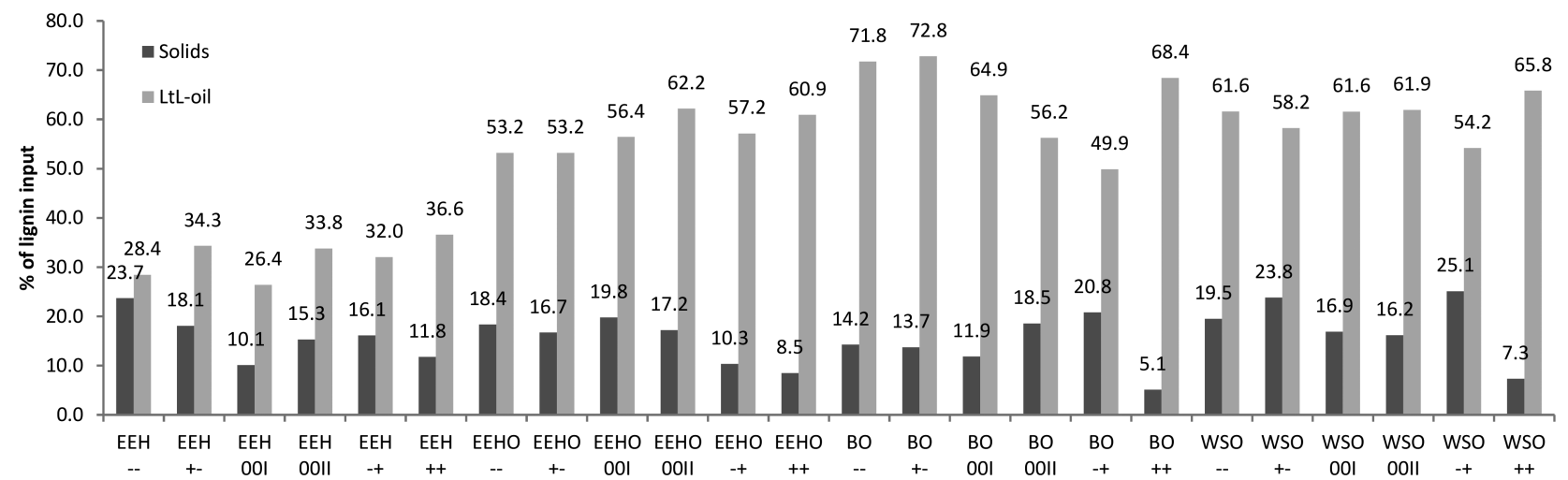

Figure 1. Column diagram showing quantitative conversion yields of lignin into LtL-oil and solid product for all experimental conditions and feedstocks.

subjected to enzymatic hydrolysis, which, unlike organosolv lignin extractions, only partially removes the carbohydrate fractions, it is expected to give a low conversion yield to bio-oil due to extensive deoxygenation giving an extensive loss in mass during solvolysis. ${ }^{28} \mathrm{O} / \mathrm{C}$ ratios and $\mathrm{H} / \mathrm{C}$ ratios for feedstocks and bio-oils are shown in a van Krevelen plot under Elemental Analysis section, Figure 6, where crude feedstock EEH falls outside the presented range because of distinctly high $\mathrm{O} / \mathrm{C}$ and $\mathrm{H} / \mathrm{C}$ ratios.

The eucalyptus crude, EEH, generally shows a higher gas fraction yield than the other feedstocks. The major source of gas is the decomposition of formic acid to $\mathrm{CO}_{2}, \mathrm{H}_{2}$, and $\mathrm{CO}$, where some part of the $\mathrm{H}_{2}$ is consumed in the conversion. Experiments number $\mathrm{EEH}--, \mathrm{EEH}-+$, and $\mathrm{EEH}++$ show a gas formation exceeding $100 \%$ of the formic acid input. This indicates gas formation during the reaction process in addition to the hydrothermal degradation of formic acid. ${ }^{34}$ Due to the higher ash content of EEH (see Table 1) one could expect a higher yield of solid residue, which is not the case as shown in Table 4. However, the eucalyptus residue shows a trend of lower average mass recovery than the other materials addressed, and this could indicate that the ash components are watersoluble to some degree. The sum of solid- and lignin product is low compared to the lignin input mass $(\sim 50 \%)$. This does also indicate that some of the bio-oil products are present as part of the aqueous phase. No analysis was performed on the aqueous phase product in this study. In general, EEH gives the lowest yields and the least optimal product distribution of the studied feedstocks.

The recovered amounts of solids (char, ash, and unreacted lignin) are relatively low for all four feedstocks ( $\leq 2.7 \%$ of total product, $5.1-25.1 \%$ (mass) of lignin input). The experimental conditions have not been optimized for minimizing the solid 


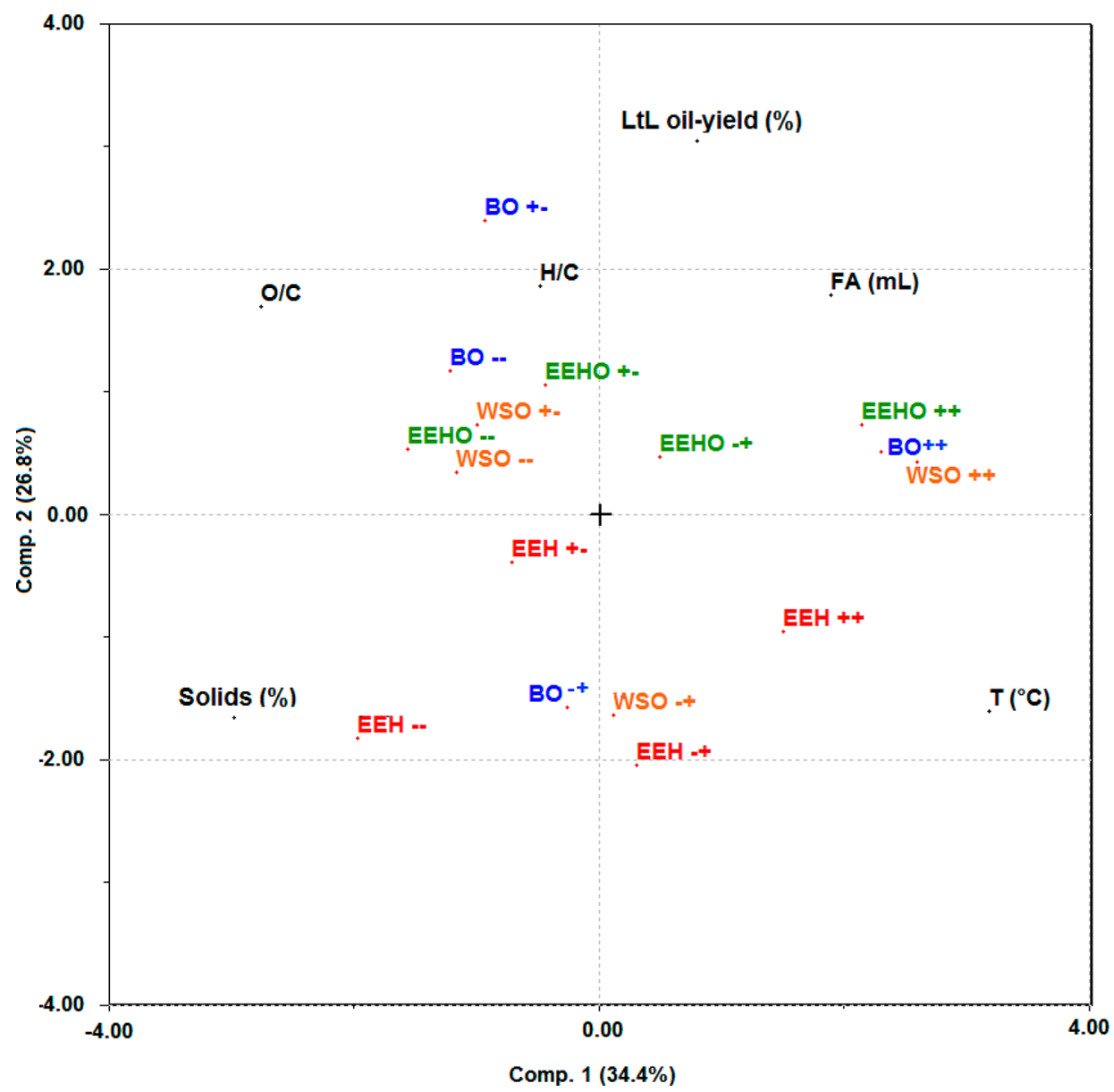

Figure 2. Biplot from principal component analysis (PCA) of the complete data set consisting of experimental variables and major response groups and excluding duplicate center point experiments. The color code is kept constant through Figures 2, 5, and 6 for visual purposes, and notations are explained in Tables 2 and 4

yields and further optimization could have the potential to minimize the solid phase organic products even further. ${ }^{28}$

Principal Component Analysis (PCA). In the defined experimental setup from Table 2 the following parameters were studied: (1) LtL-oil yield, (2), solid residue, (3) H/C ratio in bio-oil, and (4) O/C ratio in bio-oil. A successful experiment is recognized by high values for parameters 1 and 3 and low values for parameters 2 and 4 .

The experimental variables and responses were subjected to principal component analysis (PCA). Duplicate center points are excluded from the plot due to the objective being correlations between variables and responses. Figure 2 displays a biplot of the variables and major response groups. Weighting is standardized, meaning finding the standard deviation for all objects in one variable and dividing each object value with the standard deviation. The plot shows the following clear relationships: The temperature, $T\left({ }^{\circ} \mathrm{C}\right)$, is negatively correlated to $\mathrm{O} / \mathrm{C}$ ratio, illustrating high reaction temperatures giving low $\mathrm{O} / \mathrm{C}$ ratios (high degree of deoxygenation at high temperatures). The solids yield (\%) is negatively correlated with input of formic acid, FA (mL), illustrating high input of formic acid results in a low solids yield. This is a verification of deoxygenation of the lignin to generate the desired oil product and a corresponding low yield of solid residue.

There is a minor degree of negative correlation between solids yield (\%) and oil yield (\%), as anticipated. When EEH is removed from the biplot a clearer negative correlation is seen between the two responses (not shown in Figure 2). According to the tabulated responses in Table 4, experiments using EEH feedstock produce a gas fraction exceeding the input of formic acid and simultaneously giving a low yield of LtL-oil and a low sum of solid and lignin product compared to the lignin input mass (\%). The low negative correlation between solids yield and oil yield can be influenced by this trend of low oil yield and a greater gas fraction when using EEH feedstock, hence giving the observed clearer negative correlation between oil yield and solids yield when EEH is removed from the biplot.

A clear positive correlation was expected between $\mathrm{H} / \mathrm{C}$ ratio and FA (mL) since FA is thought to provide the active hydrogen for hydrogenation, but this is not prominent in the plot. However, there is a positive correlation between $\mathrm{H} / \mathrm{C}$ ratio and oil yield (\%) in the biplot that indicates successful hydrogenation in high-yield experiments. The $\mathrm{H} / \mathrm{C}$ ratio is slightly negatively correlated to temperature, $\mathrm{T}\left({ }^{\circ} \mathrm{C}\right)$, indicating the highest temperature might inhibit hydrogenation of the feedstock or, most probably, promote condensation reactions that reduce the hydrogen content of the products.

Selecting formic acid $(\mathrm{mL})$ and temperature $\left({ }^{\circ} \mathrm{C}\right)$ as variables and plotting them against each of the four responses oil yield (\%), solids yield (\%), H/C and O/C, for each feedstock in a PLS (partial least-squares) regression analysis gives a more precise indication of each variable's influence on the responses within a feedstock. In a PLS regression analysis, quantitative relations can be established between blocks of 
Table 5. Weighted Correlation Coefficients for PLS Models of Major Response Groups

\begin{tabular}{|c|c|c|c|c|c|c|}
\hline \multicolumn{7}{|c|}{ EEH } \\
\hline product property & variable range & constant & V1 FA loading (mL) & V2 reaction temperature $\left({ }^{\circ} \mathrm{C}\right)$ & $R^{a}$ & $\%$ variance explained ${ }^{b} 1$ st component \\
\hline oil yield & $26.4-36.6$ & -0.25 & 0.61 & 0.34 & 0.697 & $50.0 / 48.6$ \\
\hline solid yield & $10.1-23.7$ & 17.10 & -0.46 & -0.64 & 0.791 & $50.0 / 62.6$ \\
\hline $\mathrm{H} / \mathrm{C}$ & $1.10-1.20$ & 30.70 & 0.37 & 0.22 & 0.431 & $50.0 / 18.6$ \\
\hline $\mathrm{O} / \mathrm{C}$ & $0.17-0.23$ & 27.30 & -0.21 & -0.90 & 0.928 & $50.0 / 86.0$ \\
\hline \multicolumn{7}{|c|}{ EEHO } \\
\hline product property & variable range & constant & V1 FA loading (mL) & V2 reaction temperature $\left({ }^{\circ} \mathrm{C}\right)$ & $R^{a}$ & $\%$ variance explained ${ }^{b} 1$ st component \\
\hline Oil yield & $53.2-62.2$ & 1.16 & 0.21 & 0.70 & 0.726 & $49.7 / 52.7$ \\
\hline Solid yield & $8.5-19.8$ & 18.90 & -0.17 & -0.79 & 0.808 & $49.8 / 65.3$ \\
\hline $\mathrm{H} / \mathrm{C}$ & $1.21-1.29$ & 48.20 & -0.45 & 0.17 & 0.477 & $50.3 / 22.8$ \\
\hline $\mathrm{O} / \mathrm{C}$ & $0.15-0.23$ & 20.80 & -0.68 & -0.61 & 0.905 & $49.5 / 82.0$ \\
\hline \multicolumn{7}{|c|}{$\mathrm{BO}$} \\
\hline product property & variable range & constant & V1 FA loading (mL) & V2 reaction temperature $\left({ }^{\circ} \mathrm{C}\right)$ & $R^{a}$ & $\%$ variance explained ${ }^{b} 1$ st component \\
\hline oil yield & $49.9-72.8$ & 17.70 & 0.48 & -0.65 & 0.805 & $49.5 / 64.8$ \\
\hline solid yield & $5.1-20.8$ & 6.35 & -0.67 & -0.08 & 0.672 & $50.1 / 45.2$ \\
\hline $\mathrm{H} / \mathrm{C}$ & $1.05-1.19$ & 36.80 & 0.06 & -0.84 & 0.845 & $49.9 / 71.4$ \\
\hline $\mathrm{O} / \mathrm{C}$ & $0.19-0.30$ & 20.40 & 0.02 & -0.76 & 0.764 & $50.0 / 58.4$ \\
\hline \multicolumn{7}{|c|}{ WSO } \\
\hline product property & variable range & constant & V1 FA loading $(\mathrm{mL})$ & V2 reaction temperature $\left({ }^{\circ} \mathrm{C}\right)$ & $R^{a}$ & $\%$ variance explained ${ }^{b} 1$ st component \\
\hline Oil yield & $54.2-65.8$ & 13.60 & 0.46 & 0.01 & 0.461 & $50.0 / 21.3$ \\
\hline Solid yield & $7.3-25.1$ & 11.60 & -0.46 & -0.38 & 0.599 & $50.5 / 35.9$ \\
\hline $\mathrm{H} / \mathrm{C}$ & $1.17-1.23$ & 67.60 & 0.02 & -0.97 & 0.967 & $50.0 / 93.4$ \\
\hline $\mathrm{O} / \mathrm{C}$ & $0.13-0.21$ & 25.00 & -0.06 & -0.99 & 0.991 & $50.1 / 98.2$ \\
\hline
\end{tabular}

${ }^{a}$ Correlation coefficient for the fit of the model points to the correlation line. ${ }^{b}$ Explained variance in each model in the independent (design) and dependent (modeled) variable.

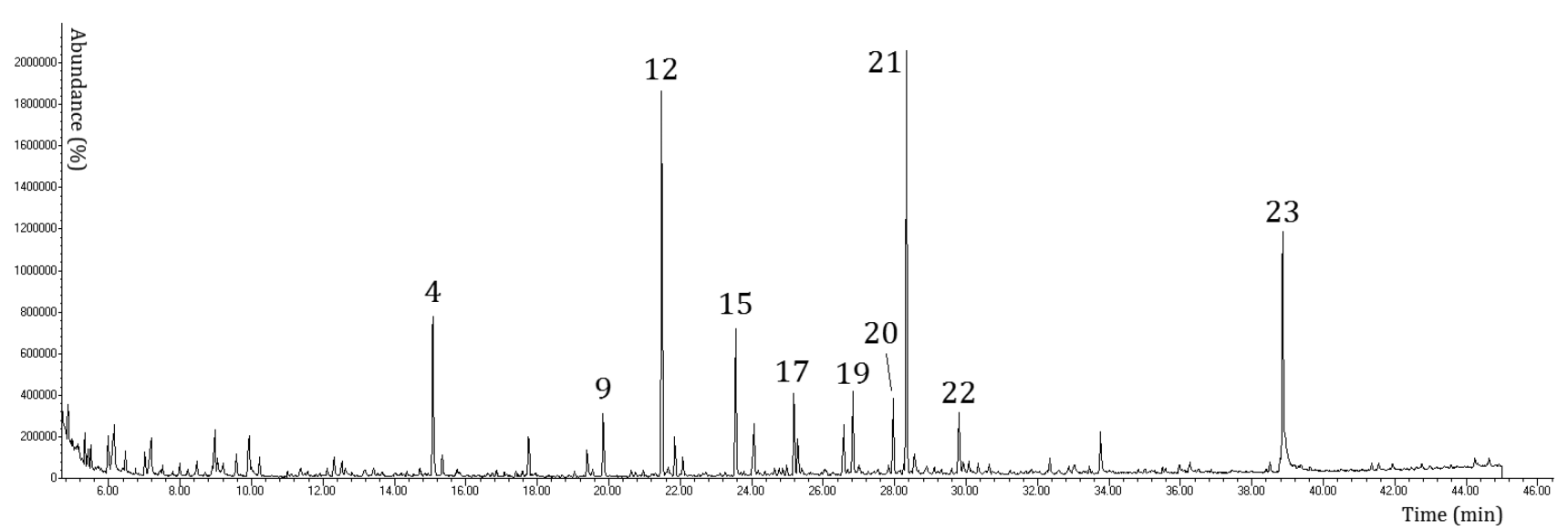

Figure 3. GC-MS chromatogram from experiment BO--. Reaction conditions: $320^{\circ} \mathrm{C}, 2 \mathrm{~h}, 0.5 \mathrm{~g}$ of $\mathrm{BO}$ lignin, $4.01 \mathrm{~g}$ of $\mathrm{H}_{2} \mathrm{O}$, and $0.61 \mathrm{~g}$ of formic acid. Labels refer to compound number as defined in Table 6 .

variables. A block of descriptor data, such as feedstock, can be analyzed for quantitative relations for a series of reaction systems/variables and a block of response data measured on these systems (responses). ${ }^{32}$ Potential hydrogenation inhibition due to temperature is observed also when using this method, but it is considerably more clear for feedstocks $\mathrm{BO}$ and WSO giving regression coefficients of $R=0.85$ and $R=0.97$, respectively. The aforementioned negative correlation between temperature and $\mathrm{O} / \mathrm{C}$ ratio is clear using PLS regression analysis within all four feedstocks, giving regression coefficients of $(\mathrm{EEH}) R=0.93$, (EEHO) $R=0.91$, (BO) $R=0.76$, and (WSO) $R=0.99$. Cross terms are excluded from the overview displayed in Table 5 because of the variables being projected with a $90^{\circ}$ angle relative to each other in every PLS plot, indicating a zero correlation.
Compound Identification with Gas Chromatography-Mass Spectrometry. Figure 3 shows a typical chromatogram of an LtL-oil and the monomeric alkyl phenols which are the most abundant compounds within the volatility range covered by the analysis. Analysis of all LtL-oils by GCMS shows similarities in the compound distributions, though the detailed substitution patterns vary with feedstock to some degree. To a large extent, the same compound types are detected in the chromatograms, but the abundance of each individual homologue is the distinguishing feature separating the various bio-oils. Thus, for each feedstock there is variation in the yields of each of the identified compounds due to reaction conditions and potentially due to lignin monomer abundance as further commented under Discussion. 
Table 6. Structural Overview from Semiquantitative GC-MS Analysis of Bio-Oils from Experiments with Minimum (--) and Maximum (++) Values for Variables V1 and V2

\begin{tabular}{|c|c|c|c|c|c|c|c|c|c|}
\hline \multirow[b]{2}{*}{ no. } & \multirow[b]{2}{*}{ compound } & \multicolumn{8}{|c|}{ area of total $(\%)$} \\
\hline & & EEH-- & $\mathrm{EEH}++$ & EEHO-- & EEHO++ & $\mathrm{BO}--$ & $\mathrm{BO}++$ & WSO-- & WSO++ \\
\hline 1 & phenol & & & & & & & & $<2$ \\
\hline 2 & 2,3-dimethyl-2-cyclopenten-1-one & & $<2$ & & & & & & \\
\hline 3 & 4-methyl phenol & & $<2$ & & $2-4$ & & & & $2-4$ \\
\hline 4 & 2-methoxy phenol (guaiacol) & $2-4$ & $2-4$ & $8-10$ & $4-6$ & $4-6$ & $4-6$ & $4-6$ & $<2$ \\
\hline 5 & 3-ethyl phenol or 4-ethyl phenol & & & & & & & $4-6$ & $6-8$ \\
\hline 6 & 2-methoxy-4-methyl phenol & $<2$ & $<2$ & $2-4$ & $<2$ & & $2-4$ & $<2$ & $<2$ \\
\hline 7 & 1,2-benzenediol (catechol) & & $<2$ & & & & & & $<2$ \\
\hline 8 & 3-methoxy-1,2-benzenediol & $<2$ & & & & & $2-4$ & $<2$ & \\
\hline 9 & 4-ethyl-2-methoxy phenol & $<2$ & $<2$ & $4-6$ & $2-4$ & $<2$ & $2-4$ & $8-10$ & $4-6$ \\
\hline 10 & 4-methyl-1,2-benzenediol & & $<2$ & & & & & & \\
\hline 11 & 2,3-dihydro- $1 H$-inden-5-ol & & $2-4$ & & $<2$ & & & & $<2$ \\
\hline 12 & 2,6-dimethoxy phenol & $2-4$ & & $6-8$ & $2-4$ & $>10$ & $6-8$ & $2-4$ & $<2$ \\
\hline 13 & 2-methoxy-4-propyl phenol & & & $2-4$ & $<2$ & & $<2$ & $<2$ & \\
\hline 14 & 4-ethylcatechol & & $2-4$ & & $<2$ & & & $<2$ & $2-4$ \\
\hline 15 & 1,2,4-trimethoxybenzene & $<2$ & & $2-4$ & & $2-4$ & $2-4$ & & \\
\hline 16 & 2-methoxy-4-(1-propenyl) phenol & & & & $2-4$ & & & & \\
\hline 17 & 1,2,3-trimethoxy-5-methylbenzene & & & $2-4$ & & $2-4$ & $<2$ & & \\
\hline 18 & homovanillyl alcohol & $<2$ & & $<2$ & & & $<2$ & & \\
\hline 19 & 3,4-diethyl-2,4-hexadienedioic acid dimethyl ester & $<2$ & & $2-4$ & & $2-4$ & $2-4$ & $<2$ & \\
\hline 20 & 2,6-dimethoxy-4-(2-propenyl) phenol & & & & & $2-4$ & & & \\
\hline 21 & dodecyl prop-2-enoate & $8-10$ & $2-4$ & $4-6$ & $<2$ & $>10$ & & $2-4$ & \\
\hline 22 & desaspinidol & & & & & $2-4$ & & & \\
\hline 23 & 9-octadecanamide & $6-8$ & & & & $8-10$ & & & \\
\hline
\end{tabular}

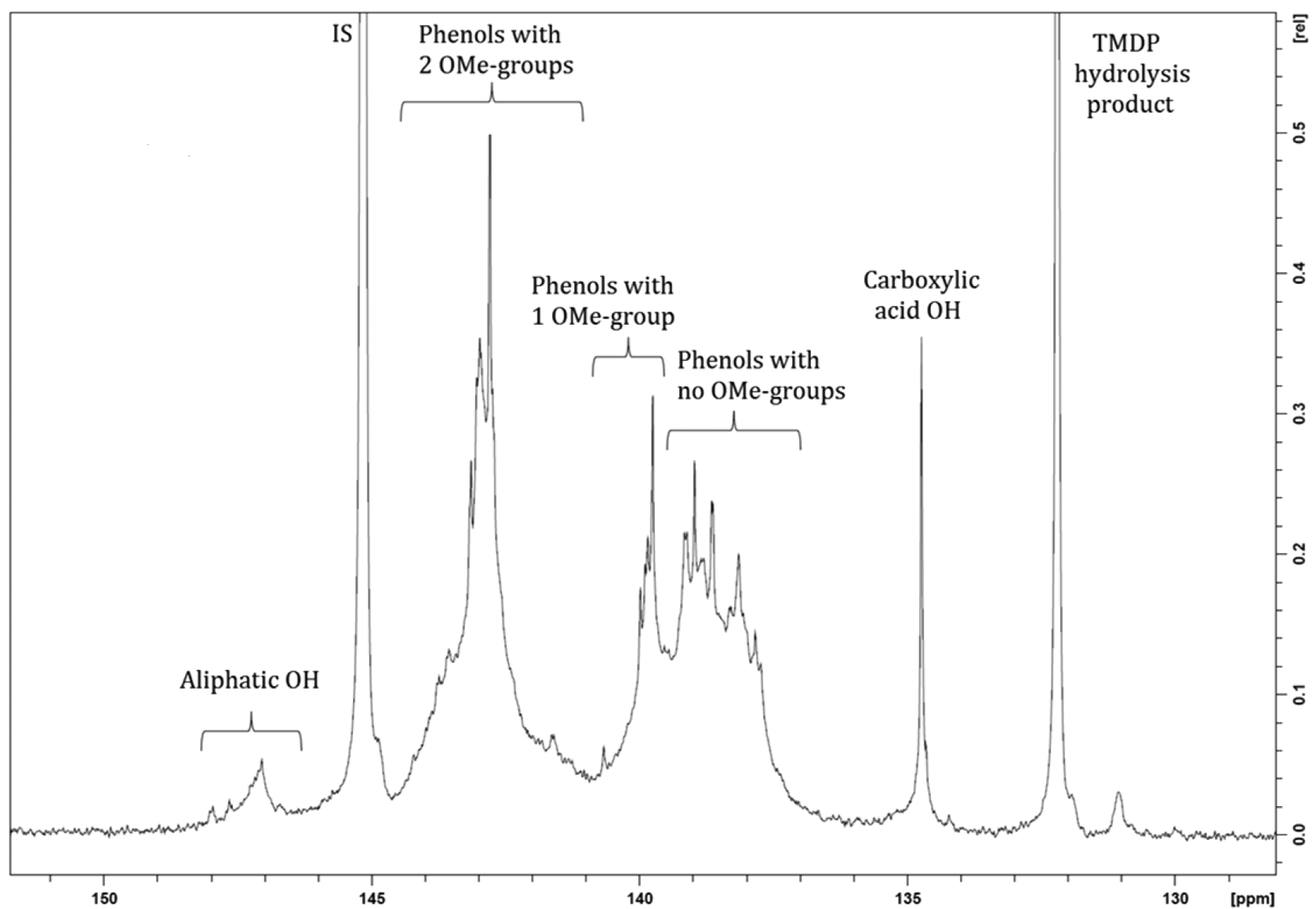

Figure 4. Example of ${ }^{31} \mathrm{P}$ NMR spectrum of a bio-oil. 


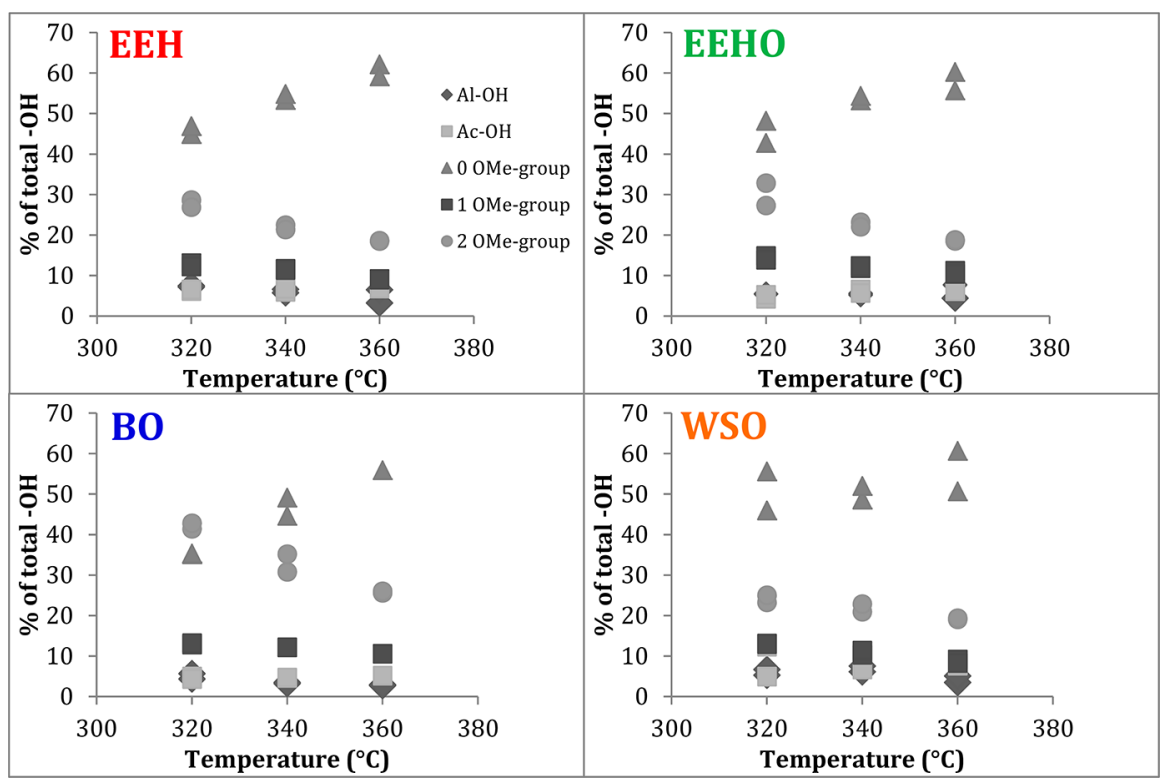

Figure 5. Relative amounts of hydroxyl groups in each lignin type relative to conversion temperature.

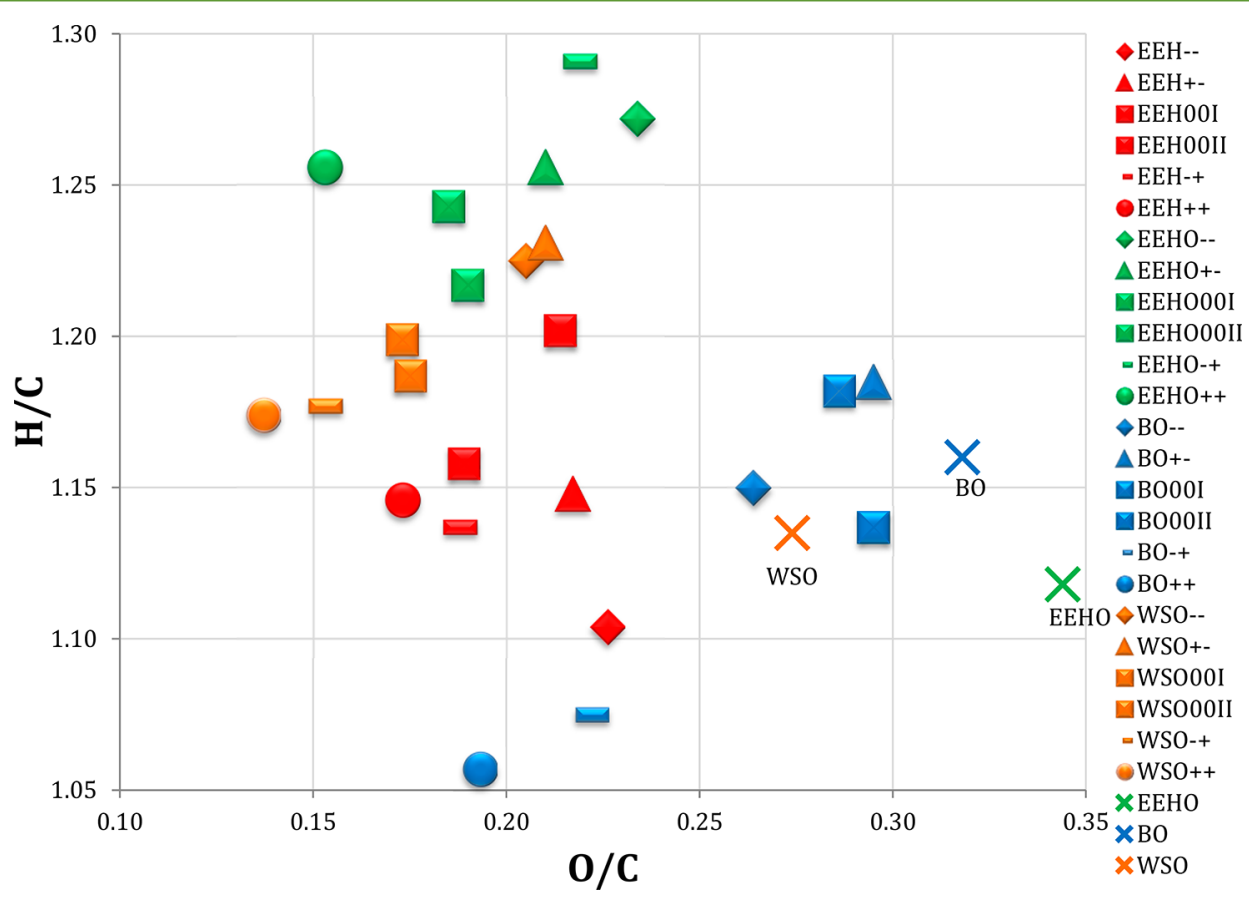

Figure 6. Van Krevelen plot showing $\mathrm{H} / \mathrm{C}$ ratio and $\mathrm{O} / \mathrm{C}$ ratio of all LtL-oils and feedstock. Each feedstock and its corresponding experiments are represented with a unique color. Crude feedstock EEH falls outside the presented range with $\mathrm{O} / \mathrm{C}$ ratio of 0.74 and $\mathrm{H} / \mathrm{C}$ ratio of 1.52 and is therefore not depicted in the figure. Conventional crude oil, with a stoichiometric $\mathrm{H} / \mathrm{C} \approx 2\left(-\mathrm{CH}_{2}-\right)$ and $\mathrm{O} / \mathrm{C} \approx 0$, also falls outside the presented area.

Table 6 shows a structural overview from semiquantitative GC-MS analysis of eight bio-oils. Only the ten most abundant compounds for each bio-oil were included in this overview. A structure overview with corresponding compound nomenclature can be found in Table S3.

${ }^{31} \mathrm{P}$ NMR. ${ }^{31} \mathrm{P}$ NMR is used to map the distribution of acidic protons in the bio-oil. Since this is a spectroscopic technique, all components in the bio-oil contribute with no limitations due to molecular weight. Individual compounds cannot be identified, but the relative proportion of each structural type in the oil mixture is quantitatively determined. A typical spectrum is given in Figure 4.
The following assignments were used for each structural group based on literature values and validated with pure compound spectra: ${ }^{35}$ aliphatic $-\mathrm{OH}, 146.3-148.3$; phenols with two methoxy groups, 141.0-144.5; phenols with one methoxy group, 139.6-140.8; phenols with no methoxy groups, 137.0-139.6; carboxylic acids, 134.0-135.3; cyclohexanol as internal standard, 144.7-145.8. The overall composition is reported as the $\%$ of each structure relative to the total signal.

The data clearly show the changes in the overall composition as a function of the reaction conditions. The proportion of compounds with two methoxy groups decreases with increasing 
temperature of the conversion. This is shown in Figure 5 for each lignin type. The overall trends are similar, showing a decrease in the phenols with one and two methoxy groups and an increase in phenols with no methoxy substituent, while the aliphatic and carboxylic hydroxyl groups show less variation. The overall proportion of each structural type depends on the origin of the lignin. The variation in formic acid input has minor effect on the hydroxyl distribution, as can be observed by the similar values for the two experiments at each temperature which only differ in FA input. A tabulated numerical distribution overview of hydroxyl group types measured by ${ }^{31} \mathrm{P}$ NMR can be found in Table S4.

Elemental Analysis. The difference in molar elemental ratio between organosolv feedstock and the respective bio-oils is limited. The degree of increase in $\mathrm{H} / \mathrm{C}$ as a result of hydrogenation of the studied organosolv lignins is limited, as seen in Figure 6, yet each feedstock's bio-oils are located above the respective feedstock in the van Krevelen plot. This represents a higher $\mathrm{H} / \mathrm{C}$ ratio for the bio-oils than for the feedstock itself and depolymerization, hence hydrogenation, is thus verified. The same trend in positioning is observed for $\mathrm{O} /$ $\mathrm{C}$ ratio, where each bio-oil is located on the left side of the respective feedstock in the plot, proving a lower $\mathrm{O} / \mathrm{C}$ ratio in the bio-oils than for the feedstock itself, thus verifying deoxygenation. Feedstock $\mathrm{BO}$ differs slightly from these observation with four of six bio-oils being located below the feedstock in the plot (lower H/C ratio than the feedstock). Crude feedstock EEH falls outside the presented range with $\mathrm{O}$ / $\mathrm{C}$ ratio of 0.74 and $\mathrm{H} / \mathrm{C}$ ratio of 1.52 and is therefore not depicted in Figure 6. For this lignin rich residue there is a very prominent hydrodeoxygenation from feedstock to LtL-oil.

Reproducibility and Mass Recovery. Within each reaction series representing the four feedstocks, two center points were performed in duplicate (X00I and X00II) to assess reproducibility of the process. The results display a variation in oil yield within each pair of duplicates ranging from $0.3-8.6 \%$ based on difference. Because of small amounts of the lignin feedstocks, the processed quantities are of small size. Hence, minimal variations during workup procedures can affect the quantitative results significantly. The solids give a lower variation of $0.7-6.7 \%$, and compared to the relative input of lignin and solvents, the variations are negligible. With this in mind, the mass recovery obtained is considered acceptable.

The GC-MS chromatograms between duplicate center points within each feedstock were virtually identical. This is also verified in Figure 5 where duplicate bio-oils have similar distribution and in the van Krevelen plot in Figure 6 where duplicate bio-oils are located close together. There is a more apparent variation in $\mathrm{H} / \mathrm{C}$ and $\mathrm{O} / \mathrm{C}$ ratio between the center points performed with feedstock $\mathrm{EEH}$ (red squares) suggesting $\mathrm{EEH}$ not to be as homogeneous as the other three feedstocks.

\section{DISCUSSION}

Grasses have a low presence of S-lignin, containing two methoxy substituents, and a higher presence of H-lignin and Glignin, containing respectively none and one methoxy substituent, than hardwoods. ${ }^{9}$ This would lead to a lower O/ $\mathrm{C}$ ratio for wheat straw (WSO) lignin feedstock compared to the hardwood lignin feedstocks examined (EEH, EEHO and BO). Hardwoods contain almost equal proportions of G-lignin and S-lignin. When examining Figure 6 the WSO feedstock is positioned with the lowest $\mathrm{O} / \mathrm{C}$ ratio of the feedstocks, in agreement with this structural indication, and correspondingly the WSO-oils are concentrated at the lower end of the $\mathrm{O} / \mathrm{C}$ axis. The trend of a decrease in phenols with one and two methoxy groups and an increase in phenols with no methoxy substituent caused by increased reaction temperature, as mentioned in ${ }^{31} \mathrm{P}$ NMR section, is not as prominent within the feedstock WSO as shown in Figure 5. This is considered a verification of the observation seen in Elemental Analysis section as lower initial oxygen content in the WSO feedstock will unfold as a less prominent decrease in oxygen content regardless of reaction temperature. This matter may also very well be the reason to the higher oil yields observed when using hardwood feedstocks, such as BO, as seen in Table 4 and Figure 1. High proportion of initial oxygen content in the feedstock and the average highest $\mathrm{O} / \mathrm{C}$ ratio in the resulting bio-oils provides additional mass to the product, thus a higher oil yield is measured.

Table 6 from GC-MS analysis in Compound identification with Gas Chromatography-Mass Spectrometry section, displaying structural names of the most abundant compounds, shows a clear decrease in phenols with one and two methoxy groups and an increase of compounds with no methoxy substituents with increasing reaction temperature when comparing the -and ++ experiments, as also observed from ${ }^{31} \mathrm{P}$ NMR. This trend is also verified by the weighting of variable $\mathrm{V} 2$ (reaction temperature) in the regression equations for $\mathrm{O} / \mathrm{C}$ ratio in Table 5 from PLS analysis in Principal Component Analysis (PCA) section, which is consistently negatively correlated.

As reported by Oregui Bengoechea et al., ${ }^{31}$ formic acid plays a key role during LtL-solvolysis, and seems to react through a formylation-elimination-hydrogenolysis mechanism that leads to the depolymerization of the biopolymer. From PLS analysis and the weighting of the regression coefficients one can conclude the amount of formic acid added in the reactions does not impact the structural composition $(\mathrm{H} / \mathrm{C}$ and $\mathrm{O} / \mathrm{C}$ ratio) to a large extent, yet the oil yields and solid yields are seen to be more affected by the input of FA. This suggests LtL-solvolysis reactions need sufficient amounts of FA to yield successful experiments with high oil yields and low solid yields, thus FA needs to be in excess relative to lignin input to provide effective depolymerization and hydrogenation. This paper does not target the investigation of reaction mechanisms during LtLsolvolysis, however, this observation suggests an upper limit of FA input to lignin ratio, which, when exceeded, does not provide further hydrodeoxygenation to give higher oil yields and lower solid yields. Too manifest such an upper limit is beneficial in the aim of reducing FA consumption.

In GC-MS analysis, Compound Identification with Gas Chromatography-Mass Spectrometry section, the LtL-oils show similarities in the compound distribution, with detailed substitution patterns varying with feedstock to some degree. At retention time 28.34 and $38.87 \mathrm{~min}$ respectively, the long chained compounds dodecyl prop-2-enoate and (Z)-9octadecanamide were tentatively identified by the NIST 2.0 library. Formation of such structures is not expected during LtL-solvolysis, as these compounds have previously not been reported. However, $\mathrm{Li}$ et al. (2009) demonstrated that the occurrence of an aliphatic fatty acid ester could be evidence of condensation reactions between compounds having $\mathrm{C}-\mathrm{O}$ or $\mathrm{C}=\mathrm{O}$ bonds derived from the lignin fragmentation. ${ }^{36} \mathrm{Kim}$ et al. (2013) reported the same observation and suggested a plausible decomposition pathway for organosolv lignin occurring in sub- and supercritical ethanol. ${ }^{15}$ Within their work ethanol was used as solvent under similar near- 
supercritical conditions, but the same structural observation occurs in this work with water as solvent. Constant et al. (2016) reported that the fatty acid ethyl esters may coprecipitate with the lignin or originate from fatty acid-lignin condensation products formed during organosolv fractionation. ${ }^{37}$ The occurrence of an amide was not expected during LtL-solvolysis. Further inspection only shows presence of this compound in the bio-oils from experiments EEH--, EEHO00I, BO--, and WSO+-. Feedstock WSO, which from elemental analysis shows nitrogen content over three times higher than the other feedstocks in this study, did not in any way stand out in this context and did thus not provide a higher abundance of this or similar compounds.

\section{CONCLUSIONS}

The general aim of aim of this Research Article was to evaluate the impact of LCBM pretreatment via organosolv lignin separation on oil yield and composition of phenolic bio-oils from subsequent thermochemical conversion of lignin. The main research question was whether lignin from organosolv pretreatment is suitable for the lignin-to-liquid-technique (LtL).

Organosolv lignin has been found to be very well-suited for LtL conversion showing high yields of the desired bio-oil and low yields of solid residue. Organosolv extraction of crude feedstock EEH (eucalyptus hardwood pretreated with enzymatic hydrolysis) gave a significant increase in bio-oil yield compared to the crude feedstock EEH. The highest oil yield was obtained from organosolv pretreated birch wood.

Elemental analysis shows an effective depolymerization and hydrodeoxygenation when comparing resulting bio-oils to the starting material. ${ }^{31} \mathrm{P}$ NMR shows a decrease in phenols with one and two methoxy groups and an increase in phenols with no methoxy substituent caused by increased reaction temperature. GC-MS analysis and correlation coefficients from PLS analysis of the experimental design verifies these observations by proving a decrease in methoxy substituents, hence $\mathrm{O} / \mathrm{C}$ ratio, with increasing temperature.

Both impure lignins such as crude feedstock EEH and pure lignins such as feedstock BO can be utilized in LtL-solvolysis, but the bio-oil yield depends on the purity of the lignin. Organosolv lignin separation provides a high purity lignin which is highly effective in LtL-solvolysis giving high bio-oil yields. The oxygen content of the resulting bio-oils thus depends on reaction conditions such as a sufficient amount of formic acid and a sufficiently high reaction temperature for effective depolymerization and hydrodeoxygenation.

The conditions used in the LtL-solvolysis of lignin conform to the requirements of sustainable chemistry in using water as solvent and converting a residual biomass into a renewable alternative to petroleum based feedstocks. The combination organosolv pretreatment and solvolytic conversion at $\mathrm{LtL}$ conditions is a novel approach that gives an exceptionally high yield of comically stable products compared to other thermochemical conversion pathways, and can thus provide a sustainable pathway toward chemicals and fuels that can be substitutes for petroleum derived products.

\section{ASSOCIATED CONTENT}

\section{S Supporting Information}

The Supporting Information is available free of charge on the ACS Publications website at DOI: 10.1021/acssuschemeng.7b03057.
Experimental parameters for optimum resolution during ${ }^{31} \mathrm{P}$ NMR analysis (Table S1), extended overview of input material, reaction conditions and product output during LtL-solvolysis (Table S2), a structure overview with corresponding compound nomenclature from GCMS analysis (Table S3), and a tabulated numerical distribution overview of hydroxyl group types measured by ${ }^{31} \mathrm{P}$ NMR (Table S4) (PDF)

\section{AUTHOR INFORMATION}

\section{Corresponding Author}

*Tel.: +47 555882 34. Fax: +47 555894 90. E-mail: camilla. lohre@uib.no.

\section{ORCID}

Camilla Løhre: 0000-0003-4761-6948

\section{Notes}

The authors declare no competing financial interest.

\section{ACKNOWLEDGMENTS}

The authors would like to thank I. J. Fjellanger for assisting with elemental analysis. We would also like to thank SEKAB for supplying eucalyptus lignin.

\section{REFERENCES}

(1) Cherubini, F. The biorefinery concept: Using biomass instead of oil for producing energy and chemicals. Energy Convers. Manage. 2010, 51 (7), 1412-1421.

(2) Cheng, F.; Brewer, C. E. Producing jet fuel from biomass lignin: Potential pathways to alkyl-benzenes and cycloalkanes. Renewable Sustainable Energy Rev. 2017, 72 (Suppl C), 673-722.

(3) Silveira, M. H. L.; Morais, A. R. C.; da Costa Lopes, A. M.; Olekszyszen, D. N.; Bogel-Łukasik, R.; Andreaus, J.; Pereira Ramos, L. Current Pretreatment Technologies for the Development of Cellulosic Ethanol and Biorefineries. ChemSusChem 2015, 8 (20), 3366-3390.

(4) García, A.; Alriols, M. G.; Llano-Ponte, R.; Labidi, J. Energy and economic assessment of soda and organosolv biorefinery processes. Biomass Bioenergy 2011, 35 (1), 516-525.

(5) Zhao, X.; Cheng, K.; Liu, D. Organosolv pretreatment of lignocellulosic biomass for enzymatic hydrolysis. Appl. Microbiol. Biotechnol. 2009, 82 (5), 815-827.

(6) Bozell, J. J.; Black, S. K.; Myers, M.; Cahill, D.; Miller, W. P.; Park, S. Solvent fractionation of renewable woody feedstocks: Organosolv generation of biorefinery process streams for the production of biobased chemicals. Biomass Bioenergy 2011, 35 (10), 4197-4208.

(7) Wildschut, J.; Smit, A. T.; Reith, J. H.; Huijgen, W. J. J. Ethanolbased organosolv fractionation of wheat straw for the production of lignin and enzymatically digestible cellulose. Bioresour. Technol. 2013, $135,58-66$.

(8) Snelders, J.; Dornez, E.; Benjelloun-Mlayah, B.; Huijgen, W. J. J.; de Wild, P. J.; Gosselink, R. J. A.; Gerritsma, J.; Courtin, C. M. Biorefining of wheat straw using an acetic and formic acid based organosolv fractionation process. Bioresour. Technol. 2014, 156, 275282.

(9) Azadi, P.; Inderwildi, O. R.; Farnood, R.; King, D. A. Liquid fuels, hydrogen and chemicals from lignin: A critical review. Renewable Sustainable Energy Rev. 2013, 21, 506-523.

(10) Kleinert, M.; Barth, T. Phenols from Lignin. Chem. Eng. Technol. 2008, 31 (5), 736-745.

(11) Stewart, D. Lignin as a base material for materials applications: Chemistry, application and economics. Ind. Crops Prod. 2008, 27 (2), 202-207.

(12) Zakzeski, J.; Bruijnincx, P. C. A.; Jongerius, A. L.; Weckhuysen, B. M. The Catalytic Valorization of Lignin for the Production of Renewable Chemicals. Chem. Rev. 2010, 110 (6), 3552-3599. 
(13) Khitrin, K. S.; Fuks, S. L.; Khitrin, S. V.; Kazienkov, S. A.; Meteleva, D. S. Lignin utilization options and methods. Russ. J. Gen. Chem. 2012, 82 (5), 977-984.

(14) Rinaldi, R.; Jastrzebski, R.; Clough, M. T.; Ralph, J.; Kennema, M.; Bruijnincx, P. C. A.; Weckhuysen, B. M. Paving the Way for Lignin Valorisation: Recent Advances in Bioengineering, Biorefining and Catalysis. Angew. Chem., Int. Ed. 2016, 55 (29), 8164-8215.

(15) Kim, J.-Y.; Oh, S.; Hwang, H.; Cho, T.-s.; Choi, I.-G.; Choi, J. W. Effects of various reaction parameters on solvolytical depolymerization of lignin in sub- and supercritical ethanol. Chemosphere 2013, 93 (9), 1755-1764.

(16) Gosselink, R. J. A.; Teunissen, W.; van Dam, J. E. G.; de Jong, E.; Gellerstedt, G.; Scott, E. L.; Sanders, J. P. M. Lignin depolymerisation in supercritical carbon dioxide/acetone/water fluid for the production of aromatic chemicals. Bioresour. Technol. 2012, $106,173-177$.

(17) Huang, S.; Mahmood, N.; Tymchyshyn, M.; Yuan, Z.; Xu, C. Reductive de-polymerization of kraft lignin for chemicals and fuels using formic acid as an in-situ hydrogen source. Bioresour. Technol. 2014, 171, 95-102.

(18) De Wild, P. J.; Huijgen, W. J. J.; Gosselink, R. J. A. Lignin pyrolysis for profitable lignocellulosic biorefineries. Biofuels, Bioprod. Biorefin. 2014, 8 (5), 645-657.

(19) Barth, T.; Kleinert, M. Motor Fuels From Biomass Pyrolysis. Chem. Eng. Technol. 2008, 31 (5), 773-781.

(20) Holmelid, B.; Kleinert, M.; Barth, T. Reactivity and reaction pathways in thermochemical treatment of selected lignin-like model compounds under hydrogen rich conditions. J. Anal. Appl. Pyrolysis 2012, 98 (0), 37-44.

(21) Gasson, J. R.; Forchheim, D.; Sutter, T.; Hornung, U.; Kruse, A.; Barth, T. Modeling the Lignin Degradation Kinetics in an Ethanol/ Formic Acid Solvolysis Approach. Part 1. Kinetic Model Development. Ind. Eng. Chem. Res. 2012, 51 (32), 10595-10606.

(22) Oregui Bengoechea, M.; Hertzberg, A.; Miletić, N.; Arias, P. L.; Barth, T. Simultaneous catalytic de-polymerization and hydrodeoxygenation of lignin in water/formic acid media with $\mathrm{Rh} / \mathrm{Al} 2 \mathrm{O}$ 3, $\mathrm{Ru} / \mathrm{Al} 2 \mathrm{O} 3$ and Pd/Al $2 \mathrm{O} 3$ as bifunctional catalysts. J. Anal. Appl. Pyrolysis 2015, 113, 713-722.

(23) Liguori, L.; Barth, T. Palladium-Nafion SAC-13 catalysed depolymerisation of lignin to phenols in formic acid and water. J. Anal. Appl. Pyrolysis 2011, 92 (2), 477-484.

(24) Zhang, K.; Pei, Z.; Wang, D. Organic solvent pretreatment of lignocellulosic biomass for biofuels and biochemicals: A review. Bioresour. Technol. 2016, 199 (SupplC), 21-33.

(25) Wang, X.; Rinaldi, R. A Route for Lignin and Bio-Oil Conversion: Dehydroxylation of Phenols into Arenes by Catalytic Tandem Reactions. Angew. Chem., Int. Ed. 2013, 52 (44), 1149911503.

(26) Sluiter, A., Hames, B.; Ruiz, R.; Scarlata, C.; Sluiter, J.; Templeton, D. Determination of Ash in Biomass. In Laboratory Analytical Procedure (LAP); National Renewable Energy Laboratory: Golden, CO, USA; p 5.

(27) Agnihotri, S.; Johnsen, I. A.; Bøe, M. S.; Øyaas, K.; Moe, S. Ethanol organosolv pretreatment of softwood (Picea abies) and sugarcane bagasse for biofuel and biorefinery applications. Wood Sci. Technol. 2015, 49 (5), 881-896.

(28) Løhre, C.; Barth, T.; Kleinert, M. The effect of solvent and input material pretreatment on product yield and composition of bio-oils from lignin solvolysis. J. Anal. Appl. Pyrolysis 2016, 119, 208-216.

(29) Løhre, C.; Vik Halleraker, H.; Barth, T. Composition of Ligninto-Liquid Solvolysis Oils from Lignin Extracted in a Semi-Continuous Organosolv Process. Int. J. Mol. Sci. 2017, 18 (1), 225.

(30) Løhre, C.; Kleinert, M.; Barth, T. Organosolv extraction of softwood combined with lignin-to-liquid-solvolysis as a semicontinuous percolation reactor. Biomass Bioenergy 2017, 99 (Suppl C), $147-155$

(31) Oregui Bengoechea, M.; Gandarias, I.; Arias, P.L.; Barth, T. Unraveling the role of formic acid and the type of solvent in the catalytic conversion of lignin: a holistic approach. ChemSusChem 2017, 10, 754-766.

(32) Carlson, R.; Carlson, J.E. Design and Optimization in Organic Synthesis, 24 ed.; Elsevier B.V.: Amsterdam, The Netherlands, 2005.

(33) Jasiukaitytė, E.; Kunaver, M.; Crestini, C. Lignin behaviour during wood liquefaction-Characterization by quantitative $31 \mathrm{P}, 13 \mathrm{C}$ NMR and size-exclusion chromatography. Catal. Today 2010, 156 (12), 23-30.

(34) Yu, J.; Savage, P. E. Decomposition of Formic Acid under Hydrothermal Conditions. Ind. Eng. Chem. Res. 1998, 37 (1), 2-10.

(35) Pu, Y.; Cao, S.; Ragauskas, A. J. Application of quantitative 31P NMR in biomass lignin and biofuel precursors characterization. Energy Environ. Sci. 2011, 4 (9), 3154-3166.

(36) Li, H.; Yuan, X.; Zeng, G.; Tong, J.; Yan, Y.; Cao, H.; Wang, L.; Cheng, M.; Zhang, J.; Yang, D. Liquefaction of rice straw in sub- and supercritical 1,4-dioxane-water mixture. Fuel Process. Technol. 2009, 90 (5), 657-663.

(37) Constant, S.; Wienk, H. L.; Frissen, A. E.; de Peinder, P.; Boelens, R.; van Es, D. S.; Grisel, R. J.; Weckhuysen, B. M.; Huijgen, W. J.; Gosselink, R. J.; Bruijnincx, P. C. New insights into the structure and composition of technical lignins: a comparative characterisation study. Green Chem. 2016, 18 (9), 2651-2665. 